\title{
Diversity Awareness And Management In Adult Education
}

Bahaudin G. Mujtaba, (E-mail: Mujtaba@nova.edu), Nova Southeastern University Lisa Mujtaba, (E-mail: Lisamujtaba@cs.com), University of Central Florida

\begin{abstract}
Effective education to all students is a moral imperative in today's diverse environment of adult learning. Educators are obligated to avoid all issues that present a conflict of interest in order to create a healthy learning environment for all students. This document provides a review of diversity related issues such as sexual harassment, self-fulfilling prophecy in relation to the diverse environment of education, diversity management concerns in learning, and adult teaching practices geared toward new adult educators of diverse student populations.
\end{abstract}

\subsection{Introduction}

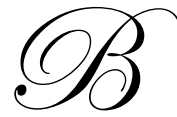

ecoming as well as being an effective educator and learning to adapt to remain as such so students can consistently learn is a moral imperative in adult education. Being an effective educator in a diverse environment of adult education requires expecting the same standards from all students regardless of their race, gender, language, and general background. Educators/teachers should not grade students differently because of their gender, nationality, or language since such differences have a negative consequence as a result of self-fulfilling prophecy. All students must earn their grades based on their actual performance in the course according to the evaluation criteria communicated. Faculty members of higher education are obligated to treat each student fairly and expect high standards from them regardless of gender, ethnicity/nationality, primary language, age, experience, disability, and other such variables.

Furthermore, teachers should and must avoid all issues that present a conflict of interest in their facultystudent relationship. For example, students must not be put in "quid pro quo" positions of doing things for faculty members as this could very well lead to cases of sexual harassment. Whether "quid pro quo" cases are intentional or unintentional, they must be avoided since they put students in a challenging position when their course grade depends on the faculty member's perception. This document discusses the basics of sexual harassment, implications of self-fulfilling prophecy concept as it is applied in the diverse environment of adult education, diversity management concerns in education, and best teaching practices while offering suggestions and effective practices for new adult educators of diverse student populations. One purpose of this document with regard to effective practices is similar to Professor Robert Preziosi's business management philosophy, which is "to find out what we're doing well and get the whole organization to do it well." As such, what works for one educator may also be helpful for other educators, provided that many of the situational variables are similar. The suggestions offer ideas so adult educators can be successful in achieving their learning outcomes based on adult learning practices that can produce positive results through application in academia. Many of the suggestions have been used both academically and in the corporate arena by trainers, managers, faculty members, and administrators of both undergraduate and graduate business programs.

\subsection{Diversity Management And Adult Education}

The student population of nearly all institutions has drastically changed from what it was twenty and thirty years ago. Some institutions have predominantly traditional students of 18 to 23 years of age attending college on a full-time basis while other institutions might have all working adult students and/or a mixture of the two. It is apparent that both student populations are much more diverse in terms of their gender, ethnicity/nationality, age, 
disability, and beliefs than they were twenty years ago. Therefore these student populations need diverse teaching skills, different experiences, and more facilitation abilities in order for them to learn best as per their learning styles. One of the needed skills and abilities would be to acknowledge their differences and actively incorporate their experiences into the learning objectives of each session. Recognizing and understanding these differences are not easy, nor automatic since they require conscious focus and a good level of comfort on the part of the faculty with cultural diversity issues. In order for educators and students to be successful, they need to become culturally competent. "Cultural competency" for all practical purposes refers to the continuous learning process that enables both educators and students to function effectively in the context of cultural differences both in academia and in the workforce.

Nearly all organizations and academic institutions have various forms of formal or mandatory training for their associates, faculty and/or staff during their initial hiring process and as an ongoing process annually. Much of this training is formally required to make sure employees of these institutions are aware that the organization expects them to treat everyone fairly. However, in many academic as well as corporate organizations, much of the training on ethics and sexual harassment topics are not reinforced through training and development. Often time, employees are provided a handbook or a website to read the material for themselves and to sign a document that they have read the material. Furthermore, some organizations that do offer a formal face-to-face training session on such important topics tend to brush through the content to make sure the legal side is covered without making sure that the material is received, understood, fully comprehended, and the specific behaviors can be successfully applied by those who attended the session. Nonetheless, many of such topics are professionally presented by experienced educators and a review of them seems relevant for adult educators.

"Sexual harassment" is often times seen as behavior that is un-welcomed (the recipient does not want it), unsolicited (the recipient did not ask for it), and repeated (the behavior is not one isolated incident). A behavior can be considered sexual harassment when submission to such conduct is made a condition of the individual's employment; when submission to, or rejection of, such conduct by an individual is used as the basis for employment decisions (such as salary increases, promotions, etc.) affecting the individual; and when such conduct has the purpose or effect of interfering with the individual's work performance or of creating an unfriendly or offensive work environment. As referred to in the introductory paragraph, quid pro quo is a condition created by the harasser in which the harassed submits to unwanted sexual and physical advances to either obtain a reward (such as a good grade without earning it through objective performance in the course) or to avoid a consequence. An actual act is not required to establish quid pro quo. Such situations must be avoided by using professional, consistent and fair treatment strategies for all students in the class. Also, adult educators should be aware and eliminate the presence of a "hostile learning environment" in their classroom. A "hostile learning environment" can be described as a situation where inappropriate remarks consistently take place and it is not corrected by the teacher/faculty member. This is a situation where insensitive and inappropriate remarks should be addressed publicly by the faculty members so everyone in the class understands the ground rules and the fact that inappropriate/insensitive comments are not appreciated nor tolerated. Educators must also avoid and eliminate the presence of sexual harassment from taking place in the classroom while maintaining a faculty-student relationship. Tangible consequences such as a lowered grade do not have to occur to substantiate the existence of sexual harassment. If a student's emotional and psychological abilities are substantially affected, there may be enough proof that sexual harassment occurred.

Today, we have a very diverse student population in terms of their background, abilities, age, language, body size, geographic location, culture, desires, learning styles, cultural conditioning, etc. Diversity describes the many unique characteristics and qualities that make a person (or student in this case) similar to or different from others. Some of these characteristics might be apparent such as skin color, hair color, body size, and general appearance. While other characteristics such as ethnicity, disability, religion, financial status, age, value, cultural background and many others may not be apparent based on first impressions. It is imperative that we do not judge students based on assumptions and must treat everyone fairly and equitably.

Diversity also encompasses the multitude of experiences, aptitudes and attitudes available in today's workforce. Diversity initiatives encourage leaders and educators to empower their associates and students as well as to tap into their wealth of differences in order to achieve synergistic results. In return, these students and associates 
will be ready to satisfy, excite and delight their diverse customers and achieve organizational effectiveness by delivering superior customer value as a result of diversity initiatives modeled in the classroom by the educators. Robert Reich, Secretary of Labor during Clinton's Administration, said, "No longer are Americans rising and falling together as if in one large national boat. We are, increasingly, in different smaller boats." So, our classroom students, customers, organizations, and societies will become progressively more diverse and we as educators need to tolerate differences, respect them, understand their nature, and educate our students about them so they can successfully work with their diverse organizations and customers. Eventually, this may lead to student's personal and professional success and they can be as successful as they so desire to be. What is success and who defines it? According to Sophocles, "success is dependent on effort" and not necessarily physical characteristics or limitations. According to Brian Tracy, Author and Speaker, "One of the most important rules for success is this: Every great success is the result of hundreds and thousands of small efforts and accomplishments that no one ever sees or appreciates." In the summer issue of Nova Southeastern University's Foresight publication (2001), Dr. Randolph Pohlman, Dean of Graduate School of Business and Entrepreneurship, wrote, "In this final issue... we strive to get at the core of what is success. By sharing with you the thoughts of various leaders, educators, and entrepreneurs, we hope to help our readers define for themselves what is success." The same is true for students; therefore, success should be defined by students based on their desires, abilities, goals and efforts. At his primary school, Malcolm X (African American leader) was told by one of his (white) teachers that he should not dream of becoming a lawyer since he could not be very successful in that job and should pursue something that requires the use of his hands. Unfortunately, due to strong biases and stereotypes such in-competency may still exist in the American Education System and we need to do everything possible to ensure it does not happen in our schools or to our students. It is not the place of the faculty member to determine how successful a student can or should be based on his/her first impression of the student or based on the student's physical/personality characteristics. Ralph Waldo Emerson said, "What is success? To laugh often and much; to win the respect of intelligent people and the affection of children; to earn the appreciation of honest critics and endure the betrayal of false friends; to appreciate beauty; to find the best in others; to leave the world a bit better, whether by a healthy child, a garden patch, or a redeemed social condition; to know even one life has breathed easier because you have lived." Simply put, success can be practicing what you preach, progressively realizing predetermined goals/ideals, and doing one's best to make worthwhile contributions to society. It is our moral imperative and obligation as educators and faculty members to (assume and) proceed as though limits to our students' abilities do not exist, unless objective evidence tells otherwise.

\subsection{Recognize And Respect Diversity In The Class}

Educators need to encourage students to think critically, add value to the class by participating, and to synergize as teams or as a whole class. Appreciating, understanding and valuing personal differences in each individual student can eliminate groupthink both in the classroom as well as in the boardroom. Groupthink is a pattern of faulty and biased decision making that occurs in groups whose members strive for agreement, among themselves, at the expense of accurately assessing information relevant to a decision. Groupthink is not a desirable objective in today's diverse and very sophisticated world of intermingled competition. This usually happens in homogeneous teams and groups because everyone's societal values tend to be similar. Research has shown that homogeneous teams are neither as creative nor as productive as heterogeneous teams when dealing with or solving complex problems. Diverse teams can achieve synergistic results if they appreciate, understand and value their differences effectively. Synergy is where the whole is greater than the sum of its parts. Ultimately, synergy is the performance gains that result when individuals, teams and departments coordinate their actions toward the same goals. Synergistic teams, colleagues, peers and departments tend to function more cooperatively and productively than if they were operating in isolation.

Synergy happens when two or more individuals working together produce more than their combined efforts individually. For example, a team of four students should produce a final project (product) that is much better than the combined results of each of the four students' work that is produced individually. Diversity awareness can help teams function harmoniously in the context of cultural differences and produces synergistic results. On the other hand, lack of diversity awareness and lack of respect for diversity can lead to negative synergy. Negative synergy is when two or more people working together produce less than what they could produce individually. According 
Stephen R. Covey, author of "The Seven Habits of Highly Effective People", negative synergy takes place when people do not respect and appreciate each other's differences.

Differences may exist in how male and female students relate to and understand material presented in the classroom. Using sports analogies to make a point in the classroom may not clarify the concepts or objectives to those who are not familiar with the rules of a specific game. This can apply to both males and females in the same way. Faculty members need to be aware of their audience and create an "inclusive learning environment." An "inclusive learning environment" is where all of the students and participants are actively involved in the learning process and can fully relate to the concepts being presented. In 1991, the Kinney Shoe Corporation realized that, gender differences (in orientation, communication, and behavior) seem subtle, yet they represent great dissimilarities in the ways that men and women function on a daily basis. Simply put, the differences can translate into an institutionalized tendency to work only within one's comfort zone, men working only with men and women working with women unless this tendency is consciously acknowledged and avoided. Many firms have established gendersensitivity training in order to create awareness and to eventually produce synergistic results among teams. During the training at The Kinney Shoe Corporation, the participants learned that females, in general, view work as a process while males usually focus on the end result and desire specific action plans and these results were further validated in 1995 by a study of over 700 male and female managers in the Central Florida area (Mujtaba, 1997) with managers. Researchers have concluded that many of the males were raised with a competitive nature, where power was the key. Furthermore, males have been found to have more of a succinct speaking style, similar to military speech, whereas, females communicated in a storytelling style. While many females prefer a circular style of group discussion so everyone can be heard, seen and acknowledged; males tend to prefer the lecture style where the group is directed and the meeting can be brought to a closure in a timely manner. Females tend to put more focus on the process (how we get there) while males may focus more on the results (where are we going and when will we get there). Such differences may exist in the classroom as well and adult educators need to recognize and capitalize on such differences appropriately as per their course learning outcomes. Understanding and respecting such differences can create an "inclusive learning environment" where groupthink is avoided and synergistic results flow infinitely as learners think for themselves and stretch their abilities beyond their existing boundaries.

\subsection{Teachers And Self-Fulfilling Prophecy: “A Class Divided” With Jane Elliot}

A video titled "The Eye of the Storm" was filmed in 1970 in an actual classroom setting in Riceville, Iowa. The children were actual third grade students and not actors. Jane Elliot, their teacher, conducted an activity that allowed her students to experience the effects of discrimination. This video also appeared on Frontline, which was conducted as a follow-up documentary by Judy Woodruff through Public Broadcasting Systems (PBS) titled "A Class Divided." The video titled "A Class Divided" is actually a follow up of the first experiment, after fifteen years, with Jane Elliot and most of her third grade students involved in the original documentary. Jane Elliot and the students discuss the impact of the experiment on all the students involved. It appears to have had positive results on her students' lives.

The actual experiment demonstrates how discrimination and stereotypes can be created rapidly in a very short period of time. On the first day of the experiment, she gives special privileges to children with blue eyes (things like second lunches, taking longer breaks, going to lunch first, etc.) and explains to the class that blue eyed people are better than brown eyed people since she along with many other intelligent people have blue eyes. Furthermore, she required the children on bottom (brown eyed children) to wear large collars that distinguished them from the smart kids. Jane Elliot kept reinforcing statements like "blue-eyed children are smarter than browneyed kids", "blue-eyed children learn faster than brown-eyed children", and "brown-eyed children are wasteful, forgetful and lazy." Pretty soon, the students started calling each other malicious names (brown-eyed, etc.) in a condescending and offensive way while treating the brown-eyed students as inferior, stupid and dumb. The superior group (actually about ninety percent of them) seemed very willing and helpful when it came to finding ways of punishing the inferior group if they got out of line and didn't follow the rules.

However, on the second day Jane Elliot told the class that she was wrong about the blue-eyed people being smarter. It is actually the opposite. So, the special privileges were taken away from the blue-eyed children and 
given to the brown-eyed children and they were continuously reinforced to be the smarter group. The blue-eyed children wore the large collars and had to sit in the back of the class since they were the inferior group on this day. It was not long before the "brown-eyed" kids started treating the blue-eyed children as inferior and started acting more confidently as they knew everything. The overall results showed that children responded to how they were treated and became what they were expected to become. The children on top (smart and privileged) consistently did better on the exams and exercises than when they were on the bottom or inferior. When the children were wearing collars, the results were very negative.

- $\quad$ Loss of self-esteem and/or self-confidence. They lost confidence in themselves in about fifteen minutes of consistent conditioning by the teacher. Bryan, one of the third graders in class, had his head down on the desk and some children were actually crying since they were labeled as inferior. The facial expressions and body language exhibited by some of the children were very negative.

- Loss of performance. The children were not able to fully concentrate on schoolwork because they were unhappy about being inferior.

- $\quad$ Conflict among them. Fighting, acting-out, name-calling, and hitting each other were a few of the obvious results because they were labeled as inferior. Revenge, finger-pointing, blame, and anti-social behavior were some of the common responses by all the students who were in the inferior group. These children had previously formed some stereotypes or "mental tapes" about people who were different from them and Jane Elliot was hoping that she could help them form new and more accurate pictures of people who didn't look like them. Jane Elliot said she learned more from the children when they were "on top" (considered superior). She learned that the superior group sought hierarchy, wanted revenge and were delighted to be superior.

- $\quad$ The superior group wanted revenge. It was survival of the fittest.

- The superior group liked superiority. Was "delighted" to place the collars on the inferior group - even the second day-it was time to get even.

- The superior group sought hierarchy. "I am better than you because..." and "you are less than us because..." mentality existed. They even looked for ways to reinforce the hierarchy by locating the yardstick and asking the teacher to use it if the "inferior" kids get out of hand. They were also encouraging Mrs. Elliot to alert the cafeteria staff to help enforce the "rules" for the inferior group since some of them may two or more lunches/servings.

Jane Elliot, the teacher who is considered to be one of the best facilitators of adult education, has now been facilitating her brown eyes/blue eyes exercise for over 30 years. In 1999, during a morning discussion with her in Washington DC at the National Multicultural Institute Conference (NMCI), she told Dr. Bahaudin Mujtaba that racial injustice is very much prevalent throughout our society and we have much work to do in order to eliminate this conditioning from the minds of our children, our students and our workforce. As a conclusion to the video and a summation of what she has learned, she offers the following comment as a concluding remark that emphasized the critical role of the educator / faculty member: "It's not how "they" are...it is how anybody will become when treated in this manner." What educators expect from their students is likely to be produced by those students. Therefore, expecting less from minorities or foreign students (whose primary language is not English) and evaluating them based on different standards would be unethical and unfair due to the concept of self-fulfilling prophecy. According to professor Dr. Dan Austin, professor of health administration and accounting, a teacher "has to be careful about making judgments and must work with students to help them find the pleasure of learning regardless of their level of passion." It is also a teacher's responsibility to help students find the pleasure of learning regardless of their nationality, race, gender or language. Because of the teacher's influence over students and/or because of the level of students respect for the teacher, it is expected that students will either live up to or down to the teacher's expectations. So, educators should avoid expecting less or even expressing the perception that they expect less from students based on preconceived notions and stereotypes associated with their gender, disabilities, place of birth, race, skin color, body size, sexual orientation, hair color, eye color, etc. The educator should expect great commitment and high quality from all students.

Stereotyping, prejudice, or biases impact the society in many ways. One way is that human beings, as individuals, may not treat some people very well because of societal conditioning and autobiographical perceptions. 
Many people experience unpleasant and unjust incidents daily solely due to some readily apparent physical characteristics. These incidents are referred to as daily indignities. Educators must make sure that such unpleasant and unjust incidents do not exist in their classrooms or work environments.

\subsection{Understand And Effectively Manage Differences}

Understanding diversity and effectively managing it is imperative in today's rapidly changing global environment of our work force. It has been said that about two thirds of the world's immigration is into the United States of America which also brings much global competition for the skills of our students. Immigration trends have greatly shifted during the past one hundred years. In the early 1900's, the majority of immigrants were from Europe; today, the majority of immigrants come from Central and Latin America, Asia, Africa, and the Middle East. Today, approximately one out of three American workers are African-American, Hispanic, or Asian; 6 out of 7 working age women are at work, and 1 out of 10 workers has some form of legally recognized disability. There are over 50 different forms of legally recognized disabilities and many of them are not apparent to the naked eye. English is expected to be a second language for the majority of Californians as well as those living in Miami, Florida.

In the mid 1980's, the Department of Labor commissioned the Hudson Institute to conduct a study on the demographic, sociological, economic, and political trends in America from post-World War II to the year 2000. The results, published in 1987 in a document titled "Work Force 2000: Work and Workers for the $21^{\text {st }}$ Century," indicated the following trends:

- $\quad$ The pool of younger workers is decreasing and the average age of workers is rising.

- $\quad$ More women are visible on the job and overall minorities comprise 1/3 of new workers. More immigrants are in the workforce and this trend is likely to continue.

- $\quad$ Service and information jobs are increasing and higher skill levels are required to compete effectively in today's global world of business.

As you can see, the challenge for businesses will be immense. Educational institutions, governments, corporations, and communities are now recognizing the necessity of valuing diversity to remain competitive in today's complex global world of business. Since the current workforce is indeed demographically diverse, leadership and management techniques of inclusion are imperative. Creating an inclusive environment (and eliminating the exclusive world of bias and stereotypes) is necessary for an effective learning environment with all learners. As a faculty member or teacher of current and future leaders and managers, a professor must create an inclusive learning environment and educate all learners in this direction as well. The classroom is the laboratory for learning such interactions with diverse colleagues and eventually co-workers.

All educators need to understand that valuing diversity requires the creation of an open, supportive, and responsive environment where differences are accepted, valued, and managed effectively toward organizational synergy. Creating such an open atmosphere in the classroom is the responsibility of the teacher. Valuing diversity means the management of a group of people with differences so that all individuals perform at their maximum potential for the achievement of organizational goals by using their unique skills, competencies, and talents. Each educator or faculty member can ask the following question and apply the appropriate answers into his/her classroom sessions: "In what specific ways, can I recognize and effectively manage diversity in the classroom to ensure a productive learning environment as well as to provide a "superior educational value for students?" The teacher along with his/her colleagues or students can brainstorm and mention specific strategies that are aligned with their vision, mission, and guiding principles that would benefit every one of the students.

\subsection{Adult Learners Require Respect And Involvement}

Successful and prepared faculty members and educators understand how adults learn best and accommodate individual needs of diverse learners. Compared to young students, some adult learners have different needs and requirements that must be accommodated in order for them to learn best. Adults have different 
motivations than their young counterparts that energize them to learn. Adults are not "pushed or forced" into the school's classrooms as is the case with many young children until they become conditioned. Adults choose to attend school and class voluntarily and have different expectations than elementary, middle school and high school children. Unlike children and teenagers, adults have many responsibilities besides learning. Because of these responsibilities that keep them away from learning at times, adults have barriers against participating in learning. Some of these barriers include lack of time, money, confidence, or interest, lack of information about opportunities to learn, scheduling problems, "red tape," and other challenges facing all adults. So, adults have a strong need to balance their learning with their critical roles at work, community and families. On the other hand, we know that adults are willing to engage in learning experiences before, after, or even during life changing events. Once convinced that change is a certainty, adults will engage in any learning that promises to help them cope with the transition and/or accelerate their progress toward worthwhile and predetermined goals. Adults who are motivated to seek out a learning experience do so primarily because they have use for the knowledge or skill being sought. Learning is a means to an end, not an end in itself. Increasing or maintaining one's sense of self-esteem and pleasure are strong secondary motivators for engaging in learning experiences.

According to researchers, learning results from stimulation of the various senses. In some people, one sense is used more than others to learn or recall information. Educators must present materials that stimulate as many of the senses as possible in order to increase learning and long-term retention. In the past, many faculty members used to provide a mid-term and a final exam to assess and evaluate the understanding of their students. The first mistake with this strategy is that the faculty is not assessing the learning on a continual basis but continues to lecture with the assumption that students are learning. The second mistake is that the students are not involved in the application of the material but rather are studying to pass the exam in the course. The third mistake is that students wait to see what is likely to be on the exam and study those concepts to increase their chances of success. The fourth mistake with this strategy is that this method encourages students to study the week before the test so the material is fresh in their minds for the test. Often this leads to the traditional cramming session before the exam, which takes away from the real learning and long-term retention of the material. Unfortunately, there are many faculty members that still use such traditional methods of assessment that used to be widespread in the educational arena. Luckily, there are many informed adult educators that use a good variety of assessment tools to actively involve adult students in the learning process so the material can be retained and reinforced for both immediate and long-term application.

Educators need to remember that students must retain the information in their memory for more than just a 24-hour period in order to benefit from the learning in the work environment. The educator's job is not finished until they have assisted the learner in retaining the information for long-term application. Long-term retention can come from being actively involved in the learning process. Retention is directly affected by the amount of thinking, application and practice that takes place during the learning process. As previously discussed, many informed adult educators use a good variety of ways to involve and assess students' learning for long-term retention and application. For example, many faculty members use different forms of quizzes to assess current knowledge and to see if the students are reading the assignments. While objective quizzes and tests assess the understanding, they can also be used to reinforce learning. Other means of involving students and assessing their understanding can come from having students present specific topics orally, assigning them a team project, having students debate each side of a situation, completing case studies, preparing and conducting role-plays, having a mid-term and final exams, asking students to prepare a term project, etc. Having students complete a number of different projects (besides exams) takes time to grade and assess their learning but it can also lead to involving them in meaningful projects that can raise their interest and result in better learning, better retention of the learning, and long-term transference of the learning. Transference of learning is the desired result of education -- it is the ability to use the information taught in a new setting. This is the overall objective of each educator and can happen when students are offered many exposures and assessment tools to understand and reinforce the material in their minds.

\subsection{Become A TRUE Educator}

Through understanding, accommodating the various learning styles of students, and the effective use of difference in the classroom, you can become a TRUE cross-cultural educator who would be able to work effectively 
in the context of cultural differences both nationally and internationally. Becoming a TRUE global educator requires:

- $\quad$ Tolerating differences,
- $\quad$ Understing differences,
- $\quad$ Examining differences for the purpose of Educating students.

The first step is usually the most difficult but a very important step in the process of becoming a TRUE educator. For example, tolerance is a personal decision and it comes from an attitude that is learned. Every human being needs to embrace the belief that each person on earth is a treasure who must be treated with respect. Everyone has the power to change his/her attitude to overcome ignorance as well as to influence his/her students, offspring, peers, and colleagues positively. It begins with a personal commitment to consciously choose one's speech and thought patterns based on intrinsically chosen values. It starts with the fact that many individuals should and can stop labeling others simply as "rednecks", "thieves", "sissies", "terrorists", or other oppressive terms based on misinformation, first impressions and/or physical appearances. As such, managers, employees and faculty members must prevent inappropriate or offensive jokes (such as Polish or gay related one-liners) from taking place in the classroom or outside of the classroom in order to create an inclusive and healthy learning environment and to become a TRUE educator. Becoming a TRUE educator will enable a person to provide a supportive and inclusive learning atmosphere/environment for students. This will result in fairness, equality, and a talented diverse workforce that can successfully function in today's global world of competitive marketplace. Some of the common benefits of incorporating diversity initiatives into the classroom can be satisfied students which will eventually benefit the society by having a talented diverse workforce with satisfied customers, high morale and commitment, low employee recruitment and retention cost, better teamwork and increased productivity, and an inclusive as well as a supportive work environment. So, be a TRUE educator, take "The Educator's Challenge" and you will make a difference.

\subsubsection{The Educator's Challenge}

Our challenge is to say something good about the people we see And to never ever let them settle for less than what they can be.

The challenge is not to shout "Raa Raa Ree, kick'em in the knee"

But to believe in them and say "Let learning be, so we can all be free."

Imagine learning flowing harmoniously as the world and sea

For that which is intrinsically imagined can most definitely be.

Personal success is a process hidden inside the educator in "me"

It can be best achieved by serving others and contributing to "we."

Our challenge is to say something good about the people we see

And to never ever let them settle for less than what they can be.

\subsection{Summary}

Diversity exists in both the student and workforce population today and will continue to increase at a growing rate. There is a moral responsibility for each faculty member to become a cultural ally and a TRUE educator with regard to today's diverse students and workforce. Valuing diversity and becoming a TRUE educator requires each person to tolerate differences, respect differences, understand differences, and to educate others about those differences in order to maximize the productivity of students in the workforce so they can remain competitive. 
Valuing diversity is not just an idea that sounds good and promotes positive publicity for the institution. Valuing diversity and the educator's genuine commitment to its thorough implementation are critical to one's success as an individual educator and to his/her student's survival in the real world. In order for educators and students to be successful, they should become culturally competent. Cultural competency refers to the continuous learning process that enables individuals (faculty and students) to function effectively in the context of cultural differences both in school and in the work environment.

Dr. Martin Luther King, Jr. dreamed that someday people would be judged by the content of their character and not by the color of their skin, not by their gender, not by their ethnic backgrounds, and not by their disabilities. He also dreamed that all individuals would sit down together at the table of brotherhood and sisterhood. Those tables are in the classrooms, conference rooms, boardrooms, cafeterias, restaurants, and manufacturing floors. The responsibility and challenge for educators are to not only take their seats at the heads of these tables but to sit there with an open mind and unclenched fists so they can be the role models for students.

Being ethical and acting as such consistently toward students and colleagues is a must for all educators and faculty members. Being ethical means expecting the same standards from each student regardless of the individual make-up of the student's background. Teachers should not grade students differently because of their race, nationality, or language. Students must earn their grades based on their performance in the course. Faculty members of higher education are required and obligated to treat each student fairly and expect high standards from each student regardless of his/her ethnicity/nationality, primary language, age, experience, disability, and other such variables. Shelby Steele, author of The Content of Our Character published in 1990, said "What is needed now is a new spirit of pragmatism in racial matters where 'disadvantaged minorities' are seen simply as American citizens who deserve complete fairness and in some cases developmental assistance, but in no case special entitlements based on "minority status." The only individuals that should be given special accommodations in the classroom, as directed by the university officials, are students with legally recognized disabilities whose needs are communicated to educators by the university officials prior to the start of the class.

Furthermore, teachers should and must avoid all issues that present a conflict of interest in their facultystudent relationship. For example, just as faculty members must not use student information for marketing or promotional purposes they must not put students in "quid pro quo" positions that are often linked to cases of sexual harassment. Many of the (students) "employers are concerned with proper employee behavior and code of conduct compliance in relation to their industries and related organizations (Mujtaba, 2003). As such, educators have the responsibility of being and becoming role models for students as these future leaders/managers are likely to mimic the actions of their teachers. Overall, this document has pointed out the moral/ethical implications of adult education and self-fulfilling prophecy to the educator in the diverse environment. It offered suggestions for adult educators and discussed suggestions for incoming college faculty members.

\subsection{References}

1. Austin, Dan (2001). An Open-Door Policy. Foresight publication by Wayne Huizenga School of Business and Entrepreneurship. Nova Southeastern University. Summer Edition.

2. Barnum, P.; Liden, D. R. And DiTomaso, N., 1995. Double Jeopardy for Women and Minorities: Pay Differences with Age. The Academy of Management Journal. Vol. 38, \# 3. June.

3. $\quad$ Covey, Stephen (1989). The Seven Habits of Highly Effective People.

4. Dupont, Kay (1997). Handling Diversity in the Workplace. AMI Publication. Forwarded by Dr. R. Roosevelt Thomas.

5. Educational Kit, (1999). Think Ability. President's Committee on Employment of People with Disabilities. See "A message from the chairman Tony Coelho."

6. $\quad$ Frey, H. William, (1999). Minority Majorities. Written in American Demographics Books. Page 6.

7. Hopkins, E. Willie (1997). Ethical Dimensions of Diversity. Sage Publications: Sage Series on Business Ethics.

8. Lieb, Stephen (1991). Principles of Adult Learning. VISION. Fall of 1991. Retrieved on December 20, 2002 through the following URL: 
http://www.hcc.hawaii.edu/intranet/committees/FacDevCom/guidebk/teachtip/adults-2.htm

9. McGlynn, A. P. (2001). "Successful beginnings for college teaching." Madison, WI: Atwood Publishing, Inc.

10. Mujtaba, B. (2003). Diversity Management and Self-Fulfilling Prophecy in Adult Education. Published in Southern Management Association Proceedings. SMA of Academy of Management. Editor: Elizabeth Wier Weatherly. November 12-16.Conference held in Clearwater, Florida.

11. Mujtaba, Bahaudin (2003). Ethical Implications of Employee Monitoring: What Leaders Should to Consider! Journal of Applied Management and Entrepreneurship. Volume 8, Number 3. July/August Issue of 2003.

12. Randolph, P. (2001). Dean's Message. Foresight publication by Wayne Huizenga School of Business and Entrepreneurship. Nova Southeastern University. Summer Edition.

13. Preziosi, R. (2001). Making a Lasting Impression: Presziosi honored as Professor of the Decade. Foresight publication by Wayne Huizenga School of Business and Entrepreneurship. Nova Southeastern University. Summer Edition.

14. Profiles in Diversity Journal. A publication for sharing diversity information. Volume 1, number 2. Summer 1999.

15. Ron and Susan Zemke, (1984). Thirty Things We Know for Sure About Adult Learning. Innovation Abstracts Vol VI, No 8, March 9, 1984.

16. Simons, George and Zuckerman, Amy J. (1994). Working Together: Succeeding in a Multicultural Organization. Revised edition. Crisp Publications. 